\title{
State of the Art in Clinical Informatics: Evidence and Examples
}

\author{
A. B. McCoy', A. Wright" ${ }^{2}$ G. Eysenbach ${ }^{3}$, B. A. Malin ${ }^{4,5}$, E. S. Patterson ${ }^{6}$, H. XU ${ }^{1}$, D. F. Sittig ${ }^{1}$ \\ ${ }^{1}$ The University of Texas School of Biomedical Informatics at Houston, Houston, Texas, USA \\ ${ }^{2}$ Brigham and Women's Hospital, Harvard Medical School, Boston, Massachusetts, USA \\ 3 University Health Network, Techna Institute, Toronto \& Institute for Health Policy, Management and \\ Evaluation, University of Toronto, Toronto, Canada \\ ${ }^{4}$ Department of Biomedical Informatics, School of Medicine, Vanderbilt University, Nashville, \\ Tennessee, USA \\ ${ }^{5}$ Department of Electrical Engineering and Computer Science, School of Engineering, Vanderbilt \\ University, Nashville, Tennessee, USA \\ ${ }^{6}$ School of Health and Rehabilitation Sciences, College of Medicine, The Ohio State University, \\ Columbus, Ohio, USA
}

\section{Summary \\ Objective: The field of clinical informatics has expanded sub- stantially in the six decades since its inception. Early research focused on simple demonstrations that health information technology (HIT) such as electronic health records (EHRS), computerized provider order entry (CPOE), and clinical decision support (CDS) systems were feasible and potentially beneficial in clinical practice. \\ Methods: In this review, we present recent evidence on clinical informatics in the United States covering three themes: 1) clinical informatics systems and interventions for providers, including EHRS, (POE, CDS, and health information exchange; 2) consumer health informatics systems, including personal health records and web-based and mobile HIT; and 3) methods and governance for clinical informatics, including EHR usability; data mining, text mining, natural language processing, privacy, and security. Results: Substantial progress has been made in demonstrating that various clinical informatics methodologies and applications improve the structure, process, and outcomes of various facets of the healthcare system. \\ Conclusion: Over the coming vears, much more will be expected from the field. As we move past the "early adopters" in Rogers' diffusion of innovations' curve through the "early majority" and into the "Iate majority," there will be a crucial need for new research methodologies and clinical applications that have been rigorously demonstrated to work (i.e., to improve health outcomes) in multiple settings with different types of patients and clinicians.}

\section{Keywords}

Informatics; evidence-based practice; medical order entry systems; decision support systems, clinical; data mining

Yearb Med Inform 2013:13-9

\section{Introduction}

The field of clinical informatics has expanded substantially in the six decades since its inception. When clinical informatics was first introduced, simple demonstrations that various information technology-enabled processes such as clinical documentation, order entry, medical diagnosis, or therapy planning were possible were sufficient to gain attention, funding, and even limited clinical use. As these techniques and technologies have become more widely available, the need for high-quality evaluations to provide scientific evidence has increased. With the recent emphasis on comparative effectiveness research [1], the need to develop new methods for and conduct rigorous evaluations of all aspects of health information technology (HIT) [2] will continue to grow.

In this paper, we present a survey of the evidence for various clinical informatics approaches. We divided the evidence into three primary themes: 1) clinical informatics systems and interventions for providers, 2) consumer health informatics systems, and 3) methods and governance for clinical informatics. The first theme, clinical informatics systems and interventions, includes two main topics: a) electronic health records (EHRs), computerized provider order entry (CPOE), and clinical decision support (CDS); and b) health information exchange (HIE). The second theme, consumer health informatics systems includes two main topics: a) personal health records (PHRs); and b) web-based and mobile HIT. The third theme, methods and governance for clinical informatics, includes three main topics: a) EHR usability; b) data mining, text mining, and natural language processing (NLP); and c) privacy and security. For each topic, we present an overview of clinical informatics approaches, a review of recent literature, and an assessment of the evidence in the United States to date.

\section{Evidence for Clinical Informatics Systems and} Interventions for Providers

\section{Electronic Health Records, Computerized Provider Order Entry, and Clinical Decision Support}

Over the past decade, clinicians and healthcare organizations have focused on implementation of HIT such as EHRs and CPOE with embedded CDS to improve quality of care and reduce costs [3]. This new focus has resulted from landmark studies [4], Institute of Medicine reports [5, 6], the American Recovery and Reinvestment Act (ARRA) stimulus with its Health Information Technology for Economic and Clinical Health (HITECH) Act [7], and the Meaningful Use Regulation, led by the Centers for Medicare and Medicaid Services and the Department of Health and Human Services [8, 9].

During this time, numerous publications have described the effect of EHRs, CPOE, and CDS on patients, processes, and cost outcomes 
$[10,11]$. Despite initially anticipated success of HIT at improving patient outcomes, investigators have had difficulty in demonstrating significant, positive findings [11]. Further, much of the literature reporting positive findings has evaluated locally developed HIT systems in large, academic medical centers $[10,12]$. However, evidence about improved process outcomes has been consistently positive; one systematic review by Bright et al. reported increased random-effects combined odds ratios for adherence to recommendations for preventive services $(\mathrm{OR}=1.42)$, ordering clinical studies $(\mathrm{OR}=1.72)$, and prescribing appropriate treatments $(\mathrm{OR}=1.575)$ [11]. On the other hand, reports of cost-effectiveness of HIT have been mixed [11]. Recent manuscripts report overall improved efficiency, although initial investment costs of HIT implementations are high [13, 14]. Also affecting costs is the Meaningful Use regulation, which includes incentive payments for those attesting to "Meaningful Use" of an EHR prior to 2015 and penalties beginning afterward for those who have not attested [8].

One unintended consequence of the increased adoption of HIT is the substantial amount of clinical data, including medications, laboratory test results, problems, allergies, notes, visits, and health maintenance items that exist within these systems and that must be reviewed by clinicians at each visit. Researchers have found that presenting such large amounts of data to clinicians trying to retrieve information about patients' care can be overwhelming, leading to frustration, inefficiency, and often errors. However, automated clinical summarization and medication reconciliation may soon be capable of addressing such problems that result during practice and care transition [15-17].

Overall, evidence for EHRs, CPOE, and CDS is positive, and little has changed in the literature over the past several years [10, 11, 13, 18]. Additional evidence from more rigorous studies in diverse settings covering additional workflow processes are necessary to fully describe the benefits or drawbacks from implementation of such HIT and to ensure that these systems improve patient care $[19,20]$.

\section{Health Information Exchange (HIE)}

HIE is the process of sharing patient information between two or more organizations, and it has been an important topic in the last few years, with considerable attention in the technical, policy and research domains [21]. In the United States, the Office of the National Coordinator for Health Information Technology (ONC) began providing substantial financial incentives to HIEs [22, 23]. ONC certification requirements mandate that all certified EHRs be able to send and receive HL7-standard continuity of care documents (CCDs) [8], and the ONC has also sponsored work on the Nationwide Health Information Network (NHIN) Direct suite of standards for sharing health information [24].

Recently, several studies looked at the effects of HIE on quality and cost outcomes. Hebel et al. found a $49 \%$ reduction in laboratory test ordering after Partners HealthCare introduced an internal HIE connecting its member hospitals [25]. Likewise, Bailey et al. studied the effect of HIE on neuroimaging in headache patients treated in emergency departments and found a significant reduction in unnecessary neuroimaging $(\mathrm{OR}=0.38)$ and increased adherence to evidence-based guidelines $(\mathrm{OR}=1.33)$ but no significant reduction in overall costs [26]. The same team, studying HIE more broadly, found a significant cost savings associated with HIE adoption, driven largely by a reduction in hospital admissions in emergency departments after HIE was introduced [27]. On the other hand, a study by Jones et al. found no association between HIE use and hospital readmission rates [28]. Surveys have found that physicians generally express positive attitudes toward the idea of HIE [29, 30], but in practice they often find that data they need are not available [29].

Despite these positive attitudes and results, HIE adoption in the United States has been fraught with challenges in financial sustainability [31,32], and, as grant funds are expended, several HIEs have shut down due to lack of funds. Alternative business models have been proposed, including a "health record bank" approach where providers submit clinical data to a patient-controlled repository [33], though the long-term business model for this type of HIE is also still uncertain. Internationally, Jha et al. studied HIE strategy and adoption in Australia, Canada, Germany, the Netherlands, New Zealand, the United Kingdom and the US and found that most countries had a national HIE strategy and some pilot programs in place, but that widespread adoption of HIE, even in the highest performing countries, was still quite low [34].
Given the apparent value of and satisfaction with HIE, coupled with more widespread adoption of interoperable health information technology, we believe HIE adoption will increase over the next several years. That said, considerable work needs to be done to identify and develop sustainable business models for HIE, and more work needs to be done to ensure that technical standards are in place to permit the exchange of coded, interoperable health data.

\section{Evidence for Consumer Health Informatics Systems}

\section{Personal Health Records (PHRs)}

PHRs are applications that are available for patients or caregivers to view and maintain a record of health status and clinical data items, such as medications and allergies, and to communicate with providers [35]. A key dimension of PHRs involves control of the clinical data and can range from stand-alone applications, under sole control of a patient, to tethered applications, under the control of the healthcare organization that provide patients with a limited view of their providers' EHR. Several of the early providers of stand-alone PHRs have recently withdrawn their offerings from the market, most notably Google Health [36]. Therefore, for this review, we will focus on tethered PHRs that provide patients with several key features, notably the ability to send and receive secure messages with their healthcare providers and the ability to review recent laboratory test results [37].

Secure messaging has been shown to improve several health outcomes, including glucose control in diabetics [38], adherence to anti-depressive medications [39], and pharmacists' management of hypertension [40]. It has also been shown to improve patient satisfaction [41], but its effect on patient resource utilization has been mixed. Specifically, Palen et al. found significant increases in both in-person and telephone-based clinical services among younger $(<50$ years old $)$ and older ( $>50$ years old) patients, as well as those with chronic conditions [42].

The evidence for the impact of giving patients direct access to their laboratory test results is still open for debate [43]. While several studies have demonstrated that pa- 
tients will use these systems, there are no studies available that investigate changes in patient health outcomes.

In summary, even though PHRs and patient portals have garnered much attention over the past 10 years, there is little high-quality evidence of their effect on improving cost, quality, or access to health care [44].

\section{Web-Based and Mobile Health Information Technology}

The Internet continues to be an important platform to empower people and to reach consumers with behavior change applications to address major public health challenges such as obesity, mental health and substance abuse. This burgeoning area is now complemented by research and development of smartphone-based mobile apps for consumers, which enable self-tracking and motivational support. Early validation studies are emerging that show mobile phones can be used as sensory tools (e.g., to measure physical activity [45] or depression [46]), or as a food diary tool [47]. When combined with behavior change approaches and what has been called "active assistance technologies" [48], these tools represent a powerful and effective way to increase population health, for example in the field of physical activity $[49,50]$. However, many existing applications available today have been described as not grounded in evidence $[50,51]$ or as not having a strong theoretical foundation $[52,53]$. A recent systematic review on the theoretical basis of behavior change applications concluded "that the effectiveness of Internet-based interventions is associated with more extensive use of theory (in particular the theory of planned behavior), inclusion of more behavior change techniques, and use of additional methods of interacting with participants (especially text messages)." [53]. Non-usage and dropout attrition of participants [54] remains a substantial problem for randomized trials in the area, and there is now an increasing evidence-base on which factors predict and increase usage and adherence to web-based and mobile applications [55-59].

The number of high-quality randomized trials in this area has increased sharply, and appraisal and consolidation of the emerging evidence is required. A recently published extension of the CONSORT statement, CONSORT-EHEALTH [60] aims to improve the reporting of trials evaluating Web-based or mobile applications, as systematic reviews conducted in this area frequently decry reporting deficiencies such as not describing the intervention or its theoretical foundations in enough detail, or not measuring or reporting exposure to the intervention.

\section{Evidence for Methods and Governance in Clinical Informatics}

\section{Health Information Technology Usability}

As new HIT systems are developed, it is important to assess human factors components, including system usability. Compromised system usability for EHRs partially explains lower EHR adoption rates in specialty areas such as pediatric care [61]. Recommendations to increase EHR adoption rates include enhancing functionality for specialty care areas $[62,63]$, improving interoperability with other HIT [64], enhancing the ability to conduct research and quality improvement, reducing interference with workflow patterns [65], improving the organization of displayed information, streamlining login procedures [66], and decreasing documentation time [67]. EHRs were found in a systematic review by Poissant et al. to have mixed impacts on documentation time for nurses and increase work time for physicians, particularly when centrally located desktop workstations are used [68]. Documentation time would likely be decreased by streamlining data entry with simplified user interfaces and optimized default settings, improving the design of alerts and reminders, including avoiding hard stops [69] and increasing the positive predictive value of alerts [70].

Usability may also affect patient safety. One study by Han et al. found an unexpected increase in patient mortality following the introduction of an EHR with usability problems in a pediatric hospital $[71,72]$. On the other hand, a later study by Longhurst et al. found a reduction in patient mortality based in large part on improvements in usability [73]. An emerging consensus is that both the system design [74] (EHR as designed) and the workflow implementation (EHR as implemented) affect patient safety. In order to improve the system design, guidelines for evaluating [75] and documenting [76] summative usability testing results have been published by the US National Institute of Standards and Technology. Likewise, the TURF (task, user, representation, and function) framework provides a set of objective measures for evaluating EHR usability as designed [77] and the SAFER (Safety Assurance Factors for Electronic Health Record Resilience) guides provide recommendations for proactive assessments of EHR usability focusing primarily on ensuring safety and effectiveness of EHRs as they are implemented [78]. For workflow implementation in pediatrics, recommendations were made to improve patient safety by reducing the risk of wrong patient errors, avoiding mode errors with weight-based dosing, and reducing delays for time-critical tasks for newborn patients [79].

For HIT systems designed for patients, additional usability issues have been found, particularly with interpreting medical terminology and graphed data [80], understanding drug-drug interaction alerts, and navigating complex login procedures. Older adult patients can have additional usability issues, such as limited vision when reading small font and giving up rather than using features that rely on interface exploration to get started [81].

Clearly, the evidence of the need for improved EHR usability is overwhelming and such improvements represent a significant challenge for informatics researchers in the coming years.

\section{Data Mining, Text Mining, and Natural Language Processing}

The international adoption of EHR systems has led to an unprecedented amount of clinical data available electronically [3, 82]. According to the US Centers for Disease Control and Prevention, more than 36 million hospital admissions and 1.3 billion ambulatory care visits are documented per year in the USA [83]. While mining EHR databases to facilitate medical research and improve clinical care is not a new area 
of research [84], it has received increased attention with the recent emphasis on widespread EHR adoption [85].

Data mining, also known as knowledge discovery in databases (KDD), is a process to find previously unknown patterns in databases. Iavindrasana et al. reviewed the state-of-the-art practices in clinical data mining, focusing on methodological issues such as data cleaning, processing, and evaluation [86]. Early evidence demonstrated that data mining technologies can be applied to healthcare data to assess treatment effectiveness [87] and to improve healthcare management [88]. More recently, studies have shown that EHR data can be used to identify comorbidities using a data-driven statistical methodology [89], detect pharmacovigilance signals [90,91], and build predictive models for disease risks $[92,93]$, surgery outcomes (94), and hospital admissions $[95,96]$.

Clinical text is a major component of EHR data and it often contains rich information describing patients. Therefore text mining is inevitable when dealing with EHR data [96]. NLP technology, which can extract structured information from free text [97], has become an essential component and a top-ranked topic in clinical informatics [98]. Researchers have been actively developing advanced clinical NLP methods, represented by works such as the i2b2 NLP Challenges [99]. Strong evidence has shown the use of NLP in facilitating clinical and translational research based on EHR data. Murff et al. conducted a study among patients undergoing surgical procedures at VA medical centers and concluded that NLP analysis had higher sensitivity on identifying postoperative complications compared with discharge coding [100]. Another study by Elkin et al. also found that an NLP-based method that used the entire encounter note was more accurate than a model based only on the chief complaint field for a bio-surveillance system of influenza [101]. A number of studies have also used NLP for automatically extracting fine-grained phenotype information from EHRs and have shown great successes in genomic [102] and pharmacogenomic [103] studies that are based on EHR-linked biobanks. In addition to supporting medical research, NLP has been used in clinical settings as well, such as to supplement structured data for clinical decision support systems [104].

Overall, the evidence is very positive for the use of data mining, text mining, and NLP in highly focused domains designed to facilitate clinical and translational research, as well as patient care.

\section{Privacy and Security}

As HIT grows in scale and scope, it is also critical to ensure the trustworthiness of the system through robust privacy and security principles. These principles should be integrated into every step of the lifecycle of health information, from initial data collection, to the use of such information in primary care, to the reuse and dissemination of patient data for secondary endeavors.

At the point of health information collection, it is necessary to enable formal specification and management of policies. These policies enable organizations to specify how they intend to process health information, as well as enable patients to indicate how they want their information to be utilized. Recent research has shown how to model the system as access zones [105], integrate personally-controlled health records with health organization-controlled EHRs [106, 107], and control the flow of information to third-parties [108].

While such control structures can be formalized, there are many ways in which health information can be breached. For instance, health information may be insufficiently protected with weak encryption or passwords. Recent research demonstrated that in 14 of 15 password-protected files containing data from Canadian clinical trials sent over email, the passwords could be cracked using commercial password recovery systems [109]. Health information may also be exposed due to poor security principles. According to statistics from the Office for Civil Rights at the U.S. Dept. of Health and Human Services (HHS), there have now been over 500 breaches at healthcare providers involving more than 500 patients [110]. While breaches are not limited to medical information, a recent econometric analysis of breaches across industry sectors showed that a compromise of medical data increases the likelihood of a settlement by $31 \%$ [111].
Ensuring that threats originating from beyond a healthcare organization are appropriately addressed, insider threats still remain. The complexity and dynamic nature of primary care settings makes it difficult to define tight access controls while maintaining clinicians' access to the required data. As such, it has become important to develop and deploy auditing techniques to monitor access to, as well as utilization of, health information. It has been shown that machine learning frameworks can refine healthcare privacy officials' knowledge of suspicious behavior into classifiers for auditing purposes [112]. Additionally, unsupervised learning techniques have been suggested to explain accesses [113] and detect deviations from normal collaborative behavior [114]. Despite such advances, recent research suggests that certain open-source medical record systems have deficiencies which may hamper auditing efforts [115].

As health information is reused in secondary settings, it is recommended that such data be de-identified prior to dissemination. A software architecture for managing access to data at varying levels of de-identification has been put into practice by i2b2 [116]. Beyond their framework, there have been specific advances in various aspects of de-identification. Given that the majority of data generated in a healthcare setting is based in natural language, there continues to be a flurry of work in the development of new free text scrubbing technologies [117-119]. Moreover, there have been recent demonstrations that these technologies can be scaled beyond traditional English-speaking countries [120]. These technologies are now being ingrained in open-source technologies [121, 122]. Other open source de-identification technologies have been developed for a medical image toolkit in DICOM format [123].

Residual personal data stored as free text can leak information that can lead to re-identification. Thus, free text, or natural language, is still not shared on a wide basis. Rather, health information is shared in field-structured form, where it can be subject to generalization, perturbation, and suppression strategies that enable quantifiable confidentiality protections. Notably, such de-identification has enabled the dissemination of health data for machine 
learning competitions [124] as well as clear demonstrations of how clinical data can be shared to support genotype association studies [125]. There remain concerns over health information and the potential for re-identification $[126,127]$. Evaluations suggest that these risks vary [128], but several reviews have shown that there is a lack of re-identification attacks of de-identified data [129]. Nonetheless, to further mitigate risk, there has been movement to erect systems that enable queries against systems that return only aggregated results in local and described healthcare environments $[130,131]$.

\section{Summary}

Over the last several years, considerable progress has been made in demonstrating that various clinical informatics methodologies and applications improve the structure, process, or outcome of various facets of the healthcare system. Over the coming years, much more will be expected from the field. As we move past the "early adopters" in Rogers' diffusion of innovations' curve [132] through the "early majority" and into the "late majority," there will be a crucial need for methodologies and applications that have been rigorously demonstrated to work in multiple settings with different types of patients.

\section{References}

1. Selby JV, Beal AC, Frank L. The Patient-Centered Outcomes Research Institute (PCORI) national priorities for research and initial research agenda. JAMA: J Am Med Assoc 2012;307(15):1583-4.

2. Stead WW, Haynes RB, Fuller S, Friedman CP, Travis LE, Beck JR, et al. Designing medical informatics research and library--resource projects to increase what is learned. J Am Med Inform Assoc 1994 Feb;1(1):28-33.

3. Jha AK, DesRoches CM, Campbell EG, Donelan $\mathrm{K}$, Rao SR, Ferris TG, et al. Use of electronic health records in U.S. hospitals. N Engl J Med 2009 Apr 16;360(16):1628-38.

4. Bates DW, Cullen DJ, Laird N, Petersen LA, Small $\mathrm{SD}$, Servi $\mathrm{D}$, et al. Incidence of adverse drug events and potential adverse drug events. Implications for prevention. ADE Prevention Study Group. JAMA 1995 Jul 5;274(1):29-34.

5. Committee on Quality of Health Care in America, Institute of Medicine. Crossing the Quality Chasm: A New Health System for the 21st Century. Nation- al Academies Press; 2001.

6. Committee on Quality of Health Care in America, Institute of Medicine. To Err Is Human: Building a Safer Health System. Kohn LT, Corrigan JM, Donaldson MS, editors. The National Academies Press; 2000.

7. Blumenthal D. Launching HITECH. N Engl J Med $2010 \mathrm{Feb} ; 362(5): 382-5$.

8. Blumenthal D, Tavenner M. The "Meaningful Use" Regulation for Electronic Health Records. N Engl J Med 2010 Aug;363(6):501-4.

9. Pacific WHORO for the W. Electronic health records: a manual for developing countries. WHO; 2006.

10. Chaudhry B, Wang J, Wu S, Maglione M, Mojica W, Roth E, et al. Systematic review: impact of health information technology on quality, efficiency, and costs of medical care. Ann Intern Med 2006 May 16;144(10):742-52

11. Bright TJ, Wong A, Dhurjati R, Bristow E, Bastian L, Coeytaux RR, et al. Effect of clinical decision-support systems: a systematic review. Ann Intern Med 2012 Jul 3;157(1):29-43.

12. Stead WW, Lin H. Computational technology for effective health care: immediate steps and strategic directions [Internet]. National Academy Press; 2009 [cited 2012 Dec 16]. Available from: http:// books.google.com/books?hl=en\&lr=\&id=HUAXQzIPxV8C\&oi=fnd\&pg=PT1\&dq=stead + lin + computational+technology\&ots $=$ Sh6SFpD3Lc\&sig=yfcG1YWKWdrHrJT9faa7z5EeGC0

13. Buntin MB, Burke MF, Hoaglin MC, Blumenthal D. The Benefits Of Health Information Technology: A Review Of The Recent Literature Shows Predominantly Positive Results. Health Aff. 2011 Mar 1;30(3):464-71

14. Fleming NS, Culler SD, McCorkle R, Becker ER, Ballard DJ. The Financial And Nonfinancial Costs Of Implementing Electronic Health Records In Primary Care Practices. Health Aff 2011 Mar 1;30(3):481-9.

15. Feblowitz JC, Wright A, Singh H, Samal L, Sittig DF. Summarization of clinical information: a conceptual model. J Biomed Inform 2011 Aug;44(4):688-99.

16. Laxmisan A, McCoy AB, Wright A, Sittig DF. Clinical Summarization Capabilities of Commercially-available and Internally-developed Electronic Health Records. Appl Clin Inform 2012 Feb 22:3(1):80-93.

17. Kwan JL, Lo L, Sampson M, Shojania KG. Medication Reconciliation During Transitions of Care as a Patient Safety StrategyA Systematic Review. Ann Intern Med 2013 Mar 5;158(5 Part 2):397-403.

18. Veer AJ de, Fleuren MA, Bekkema N, Francke AL. Successful implementation of new technologies in nursing care: a questionnaire survey of nurse-users. BMC Med Inform Decis Mak 2011 Oct 27;11(1):67.

19. Committee on Patient Safety and Health Information Technology, Institute of Medicine. Health IT and Patient Safety: Building Safer Systems for Better Care. The National Academies Press; 2012.

20. McCoy AB, Waitman LR, Lewis JB, Wright JA, Choma DP, Miller RA, et al. A framework for evaluating the appropriateness of clinical decision support alerts and responses. J Am Med Inform Assoc 2012 May 1;19(3):346-52.

21. Vest JR, Gamm LD. Health information exchange: persistent challenges and new strategies. J Am Med Inform Assoc 2010 May 1;17(3):288-94.
22. Williams C, Mostashari F, Mertz K, Hogin E, Atwal P. From the Office of the National Coordinator: the strategy for advancing the exchange of health information. Health Aff (Millwood) 2012 Mar;31(3):527-36

23. Sittig DF, Joe JC. Toward a statewide health information technology center (abbreviated version). South Med J 2010 Nov;103(11):1111-4.

24. Kuperman GJ. Health-information exchange: why are we doing it, and what are we doing? J Am Med Inform Assoc 2011 Oct;18(5):678-82.

25. Hebel E, Middleton B, Shubina M, Turchin A. Bridging the chasm: effect of health information exchange on volume of laboratory testing. Arch Intern Med 2012 Mar 26;172(6):517-9.

26. Bailey JE, Wan JY, Mabry LM, Landy SH, Pope RA, Waters TM, et al. Does Health Information Exchange Reduce Unnecessary Neuroimaging and Improve Quality of Headache Care in the Emergency Department? J Gen Intern Med 2013 Feb;28(2):176-83

27. Frisse ME, Johnson KB, Nian H, Davison CL, Gadd CS, Unertl KM, et al. The financial impact of health information exchange on emergency department care. J Am Med Inform Assoc 2012 Jun;19(3):328-33.

28. Jones SS, Friedberg MW, Schneider EC. Health information exchange, Health Information Technology use, and hospital readmission rates. AMIA Annu Symp Proc 2011;2011:644-53.

29. Hincapie AL, Warholak TL, Murcko AC, Slack M, Malone DC. Physicians' opinions of a health information exchange. J Am Med Inform Assoc 2011 Feb;18(1):60-5.

30. Wright A, Soran C, Jenter CA, Volk LA, Bates DW, Simon SR. Physician attitudes toward health information exchange: results of a statewide survey. J Am Med Inform Assoc 2010 Feb;17(1):66-70.

31. Adler-Milstein J, Bates DW, Jha AK. A survey of health information exchange organizations in the United States: implications for meaningful use. Ann Intern Med 2011 May 17;154(10):666-71.

32. Adler-Milstein J, McAfee AP, Bates DW, Jha AK The state of regional health information organizations: current activities and financing. Health Aff (Millwood) 2008 Feb;27(1):w60-69.

33. Yasnoff WA SL. PUtting health it on the path to success. JAMA 2013 Mar 13;309(10):989-90.

34. Jha AK, Doolan D, Grandt D, Scott T, Bates DW. The use of health information technology in seven nations. Int J Med Inform 2008 Dec; 77(12):848-54

35. Sittig DF. Personal health records on the internet: a snapshot of the pioneers at the end of the 20th Century. Int J Med Inform 2002 Apr;65(1):1-6.

36. Google Health [Internet]. [cited 2012 Dec 3]. Available from: http://www.google.com/intl/en_us/ health/faq.html

37. Goldzweig CLCL, Towfigh AAAA, Paige NMNM, Orshansky GG, Haggstrom DADA, Beroes JMJM, et al. Systematic Review: Secure Messaging Between Providers and Patients, and Patients' Access to Their Own Medical Record: Evidence on Health Outcomes, Satisfaction, Efficiency and Attitudes. Washington (DC): Department of Veterans Affairs (US); 2012.

38. Zhou YY, Kanter MH, Wang JJ, Garrido T. Improved quality at Kaiser Permanente through e-mail between physicians and patients. Health Aff (Millwood) $2010 \mathrm{Jul} ; 29(7): 1370-5$. 
39. Simon GE, Ralston JD, Savarino J, Pabiniak C, Wentzel C, Operskalski BH. Randomized trial of depression follow-up care by online messaging. J Gen Intern Med 2011 Jul;26(7):698-704.

40. Green BB, Cook AJ, Ralston JD, Fishman PA, Catz SL, Carlson J, et al. Effectiveness of home blood pressure monitoring, Web communication, and pharmacist care on hypertension control: a randomized controlled trial. JAMA 2008 Jun 25;299(24):2857-67.

41. Leong SL, Gingrich D, Lewis PR, Mauger DT, George JH. Enhancing doctor-patient communication using email: a pilot study. J Am Board Fam Pract 2005 Jun;18(3):180-8.

42. Palen TE, Ross C, Powers JD, Xu S. Association of online patient access to clinicians and medical records with use of clinical services. JAMA 2012 Nov 21;308(19):2012-9.

43. Davis Giardina T, Singh H. Should patients get direct access to their laboratory test results? An answer with many questions. JAMA 2011 Dec 14;306(22):2502-3.

44. Ammenwerth E, Schnell-Inderst P, Hoerbst A. The Impact of Electronic Patient Portals on Patient Care: A Systematic Review of Controlled Trials. J Med Internet Res [Internet] 2012 Nov 26 [cited 2012 Dec 14];14(6). Available from: http://www.ncbi. nlm.nih.gov/pmc/articles/PMC3510722/

45. Wu W, Dasgupta S, Ramirez EE, Peterson C, Norman GJ. Classification accuracies of physical activities using smartphone motion sensors. J Med Internet Res 2012;14(5):e130.

46. Burns MN, Begale M, Duffecy J, Gergle D, Karr CJ, Giangrande E, et al. Harnessing context sensing to develop a mobile intervention for depression. J Med Internet Res 2011;13(3):e55.

47. Daugherty BL, Schap TE, Ettienne-Gittens R, Zhu FM, Bosch M, Delp EJ, et al. Novel technologies for assessing dietary intake: evaluating the usability of a mobile telephone food record among adults and adolescents. J Med Internet Res 2012;14(2):e58.

48. Kennedy CM, Powell J, Payne TH, Ainsworth J, Boyd A, Buchan I. Active assistance technology for health-related behavior change: an interdisciplinary review. J Med Internet Res 2012;14(3):e80.

49. Fanning J, Mullen SP, McAuley E. Increasing physical activity with mobile devices: a meta-analysis. J Med Internet Res 2012;14(6):e161

50. Lau PWC, Lau EY, Wong DP, Ransdell L. A systematic review of information and communication technology-based interventions for promoting physical activity behavior change in children and adolescents. J Med Internet Res 2011;13(3):e48.

51. West JH, Hall PC, Hanson CL, Barnes MD, Giraud-Carrier C, Barrett J. There's an app for that: content analysis of paid health and fitness apps. J Med Internet Res 2012;14(3):e72.

52. Murray E. Web-Based Interventions for Behavior Change and Self-Management: Potential, Pitfalls, and Progress. Medicine 2.0. 2012;1(2):e3.

53. Webb TL, Joseph J, Yardley L, Michie S. Using the internet to promote health behavior change: a systematic review and meta-analysis of the impact of theoretical basis, use of behavior change techniques, and mode of delivery on efficacy. J Med Internet Res 2010;12(1):e4.

54. Eysenbach G. The law of attrition. J Med Internet Res 2005;7(1):e11

55. Kelders SM, Kok RN, Ossebaard HC, Van Gemert-Pijnen JE. Persuasive system design does mat- ter: a systematic review of adherence to web-based interventions. J Med Internet Res 2012;14(6):e152.

56. Lehto T, Oinas-Kukkonen H. Persuasive features in web-based alcohol and smoking interventions: a systematic review of the literature. J Med Internet Res 2011;13(3):e46.

57. Cugelman B, Thelwall M, Dawes P. Online interventions for social marketing health behavior change campaigns: a meta-analysis of psychological architectures and adherence factors. J Med Internet Res 2011;13(1):e17.

58. Brouwer W, Kroeze W, Crutzen R, De Nooijer J, De Vries NK, Brug J, et al. Which intervention characteristics are related to more exposure to internet-delivered healthy lifestyle promotion interventions? A systematic review. J Med Internet Res 2011;13(1):e2.

59. Morrison LG, Yardley L, Powell J, Michie S. What design features are used in effective e-health interventions? A review using techniques from Critical Interpretive Synthesis. Telemed J E Health 2012 Mar;18(2):137-44

60. Eysenbach G. CONSORT-EHEALTH: improving and standardizing evaluation reports of Web-based and mobile health interventions. J Med Internet Res 2011;13(4):e126

61. Nakamura MM, Ferris TG, DesRoches CM, Jha AK. Electronic health record adoption by children's hospitals in the United States. Arch Pediatr Adolesc Med 2010 Dec;164(12):1145-51

62. Spooner SA. Special requirements of electronic health record systems in pediatrics. Pediatrics 2007 Mar;119(3):631-7.

63. Shiffman RN, Spooner SA, Kwiatkowski K, Brennan PF. Information technology for children's health and health care: report on the Information Technology in Children's Health Care Expert Meeting, September 21-22, 2000. J Am Med Inform Assoc 2001 Dec;8(6):546-51.

64. Hinman AR, Davidson AJ. Linking children's health information systems: clinical care, public health, emergency medical systems, and schools. Pediatrics 2009 Jan;123 Suppl 2:S67-73.

65. Rose AF, Schnipper JL, Park ER, Poon EG, Li Q, Middleton B. Using qualitative studies to improve the usability of an EMR. J Biomed Inform 2005 Feb;38(1):51-60.

66. Khajouei R, Jaspers MWM. CPOE system design aspects and their qualitative effect on usability. Stud Health Technol Inform 2008;136:309-14.

67. Saleem JJ, Patterson ES, Militello L, Anders S, Falciglia M, Wissman JA, et al. Impact of clinical reminder redesign on learnability, efficiency, usability, and workload for ambulatory clinic nurses. J Am Med Inform Assoc 2007 Oct;14(5):632-40.

68. Poissant L, Pereira J, Tamblyn R, Kawasumi Y. The impact of electronic health records on time efficiency of physicians and nurses: a systematic review. J Am Med Inform Assoc 2005 Oct;12(5):505-16.

69. Strom BL, Schinnar R, Aberra F, Bilker W, Hennessy S, Leonard CE, et al. Unintended effects of a computerized physician order entry nearly hard-stop alert to prevent a drug interaction: a randomized controlled trial. Arch Intern Med 2010 Sep 27;170(17):1578-83.

70. Baysari MT, Reckmann MH, Li L, Day RO, Westbrook JI. Failure to utilize functions of an electronic prescribing system and the subsequent generation of "technically preventable" computerized alerts. J Am Med Inform Assoc 2012 Nov 1;19(6):1003-10.
71. Han YY, Carcillo JA, Venkataraman ST, Clark RSB, Watson RS, Nguyen TC, et al. Unexpected increased mortality after implementation of a commercially sold computerized physician order entry system. Pediatrics 2005 Dec;116(6):1506-12.

72. Sittig DF, Ash JS, Zhang J, Osheroff JA, Shabot MM. Lessons from "Unexpected increased mortality after implementation of a commercially sold computerized physician order entry system". Pediatrics 2006 Aug;118(2):797-801.

73. Longhurst CA, Parast L, Sandborg CI, Widen E, Sullivan J, Hahn JS, et al. Decrease in hospital-wide mortality rate after implementation of a commercially sold computerized physician order entry system. Pediatrics $2010 \mathrm{Jul} ; 126(1): 14-21$.

74. Hales J, Ash JS, Lehmann CU, Longhurst CA, Spooner SA. Pediatric safety risks from unintended consequences of the use of EMRs designed for adults. AMIA Annu Symp Proc 2012;1512.

75. Lowry SZ, Quinn MT, Ramaiah M, Schumacher RM, Patterson ES, North R, et al. Technical Evaluation, Testing, and Validation of the Usability of Electronic Health Records. National Institute of Standards and Technology; 2012.

76. Schumacher R, Lowry S. Customized common industry format template for electronic health record usability testing. National Institute of Standards and Technology NISTIR; 2010. p. 7742.

77. Zhang J, Walji MF. TURF: toward a unified framework of EHR usability. J Biomed Inform 2011 Dec;44(6):1056-67.

78.Singh H, Ash JS, Sittig DF. Safety Assurance Factors for Electronic Health Record Resilience (SAFER): study protocol. BMC Med Inform Decis Mak 2013 Apr 12;13:46.

79. Lowry SZ, Quinn MT, Ramaiah M, D. Brick, E. S. Patterson, J. Zhang, et al. A Human Factors Guide to Enhance EHR Usability of Critical User Interactions when Supporting Pediatric Patient Care. National Institute of Standards and Technology; 2012.

80. Britto MT, Jimison HB, Munafo JK, Wissman J, Rogers ML, Hersh W. Usability testing finds problems for novice users of pediatric portals. J Am Med Inform Assoc 2009 Oct;16(5):660-9.

81. Chun YJ, Patterson PE. A usability gap between older adults and younger adults on interface design of an Internet-based telemedicine system. Work 2012 Jan 1;41(0):349-52.

82. Shea S, Hripcsak G. Accelerating the use of electronic health records in physician practices. NEngl J Med 2010 Jan 21;362(3):192-5.

83. FASTSTATS - Homepage [Internet]. [cited 2012 Dec 14]. Available from: http://www.cdc.gov/nchs/ fastats/

84. Warner HR, Toronto AF, Veasey LG, Stephenson R. A mathematical approach to medical diagnosis: application to congenital heart disease.1961. MD Comput 1992 Feb;9(1):43-50.

85. Jensen PB, Jensen LJ, Brunak S. Mining electronic health records: towards better research applications and clinical care. Nat Rev Genet 2012 Jun;13(6):395-405.

86. Iavindrasana J, Cohen G, Depeursinge A, Müller $\mathrm{H}$, Meyer R, Geissbuhler A. Clinical data mining: a review. Yearb Med Inform 2009;121-33.

87. Milley A. Healthcare and data mining. Health Manag Technol 2000;21(8):44-7.

88. Silver M, Sakata T, Su HC, Herman C, Dolins SB, O'Shea MJ. Case study: how to apply data mining techniques in a healthcare data warehouse. 
J Healthc Inf Manag 2001;15(2):155-64.

89. Roque FS, Jensen PB, Schmock H, Dalgaard M, Andreatta M, Hansen T, et al. Using electronic patient records to discover disease correlations and stratify patient cohorts. PLoS Comput Biol 2011;7(8):e1002141.

90. Haerian K, Varn D, Vaidya S, Ena L, Chase HS, Friedman C. Detection of pharmacovigilance-related adverse events using electronic health records and automated methods. Clin Pharmacol Ther 2012 Aug;92(2):228-34.

91. Coloma PM, Schuemie MJ, Trifirò G, Gini R, Herings R, Hippisley-Cox J, et al. Combining electronic healthcare databases in Europe to allow for large-scale drug safety monitoring: the EUADR Project. Pharmacoepidemiol Drug Saf 2011 Jan;20(1):1-11.

92. Jiang X, Boxwala AA, El-Kareh R, Kim J, Ohno-Machado L. A patient-driven adaptive prediction technique to improve personalized risk estimation for clinical decision support. Journal of the American Medical Informatics Association: J Am Med Inform Assoc 2012 Jun 1;19(e1):e137-e144.

93. Himes BE, Dai Y, Kohane IS, Weiss ST, Ramoni MF. Prediction of chronic obstructive pulmonary disease (COPD) in asthma patients using electronic medical records. J Am Med Inform Assoc 2009 Jun;16(3):371-9.

94. Sarin P, Urman RD, Ohno-Machado L. An improved model for predicting postoperative nausea and vomiting in ambulatory surgery patients using physician-modifiable risk factors. J Am Med Inform Assoc 2012 Nov 1;19(6):995-1002.

95. Description - Heritage Health Prize [Internet]. [cited 2012 Dec 3]. Available from: http://www. heritagehealthprize.com/c/hhp

96. Fialho AS, Cismondi F, Vieira SM, Reti SR, Sousa JMC, Finkelstein SN. Data mining using clinical physiology at discharge to predict ICU readmissions. Expert Syst Appl 2012 Dec; 39(18):13158-65.

97. Meystre S. Electronic patient records: some answers to the data representation and reuse challenges. Findings from the section on Patient Records. Yearb Med Inform 2007;47-9.

98. Kim H-E, Jiang X, Kim J, Ohno-Machado L. Trends in biomedical informatics: most cited topics from recent years. J Am Med Inform Assoc 2011 Dec 16;18(Suppl 1):i166-i170.

99. Chapman WW, Nadkarni PM, Hirschman L, D'Avolio LW, Savova GK, Uzuner O. Overcoming barriers to NLP for clinical text: the role of shared tasks and the need for additional creative solutions. J Am Med Inform Assoc 2011 Oct;18(5):540-3.

100. Murff HJ, FitzHenry F, Matheny ME, Gentry N, Kotter KL, Crimin K, et al. Automated identification of postoperative complications within an electronic medical record using natural language processing. JAMA 2011 Aug 24;306(8):848-55.

101. Elkin PL, Froehling DA, Wahner-Roedler DL, Brown SH, Bailey KR. Comparison of natural language processing biosurveillance methods for identifying influenza from encounter notes. Ann Intern Med 2012 Jan 3;156(1 Pt 1):11-8.

102. Denny JC, Crawford DC, Ritchie MD, Bielinski SJ, Basford MA, Bradford Y, et al. Variants near FOXE1 are associated with hypothyroidism and other thyroid conditions: using electronic medical records for genome- and phenome-wide stud- ies. Am J Hum Genet 2011 Oct 7;89(4):529-42.

103. Xu H, Jiang M, Oetjens M, Bowton EA, Ramirez $\mathrm{AH}$, Jeff JM, et al. Facilitating pharmacogenetic studies using electronic health records and natural-language processing: a case study of warfarin. J Am Med Inform Assoc 2011 Aug;18(4):387-91.

104. Demner-Fushman D, Chapman WW, McDonald CJ. What can natural language processing do for clinical decision support? J Biomed Inform 2009 Oct;42(5):760-72.

105. Ardagna CA, De Capitani di Vimercati S, Foresti S, Grandison TW, Jajodia S, Samarati P. Access control for smarter healthcare using policy spaces. Computers \& Security 2010 Nov:29(8):848-58

106. Blobel B. Ontology driven health information systems architectures enable pHealth for empowered patients. Int J Med Inform 2011 Feb;80(2):e17-25.

107. Heinze O, Birkle M, Köster L, Bergh B. Architecture of a consent management suite and integration into IHE-based Regional Health Information Networks. BMC Med Inform Decis Mak 2011;11:58

108. Haas S, Wohlgemuth S, Echizen I, Sonehara N, Müller G. Aspects of privacy for electronic health records. Int J Med Inform 2011 Feb;80(2):e26-31.

109. El Emam K, Moreau K, Jonker E. How Strong are Passwords Used to Protect Personal Health Information in Clinical Trials? J Med Internet Res 2011 Feb 11;13(1):e18.

110. Breaches Affecting 500 or More Individuals [Internet]. Office for Civil Rights, U.S. Dept. of Health and Human Services; Available from: http://www.hhs.gov/ocr/privacy/hipaa/administrative/breachnotificationrule/breachtool.html

111. Romanosky S, Hoffman D, Acquisti A. Empirical Analysis of Data Breach Litigation. Temple University Legal Studies Research Paper; 2012. p. 30.

112. Boxwala AA, Kim J, Grillo JM, Ohno-Machado L. Using statistical and machine learning to help institutions detect suspicious access to electronic health records. J Am Med Inform Assoc 2011 Aug;18(4):498-505.

113. Fabbri D, LeFevre K, Hanauer DA. Explaining accesses to electronic health records. Proceedings of the 2011 workshop on Data mining for medicine and healthcare [Internet]. 2011 [cited 2012 Dec 3]. p. 10-7. Available from: http:// dl.acm.org/citation.cfm?id=2023585

114. Chen Y, Nyemba S, Malin BA. Auditing medical record accesses via healthcare interaction networks. AMIA Annu Symp Proc 2012;93-102.

115. King JT, Smith B, Williams L. Modifying without a trace: general audit guidelines are inadequate for open-source electronic health record audit mechanisms. Proceedings of the 2nd ACM SIGHIT symposium on International health informatics [Internet]. 2012 [cited 2012 Dec 3]. p. 305-14. Available from: http://dl.acm.org/ citation. $. \mathrm{fm} ? \mathrm{id}=2110399$

116. Murphy SN, Gainer V, Mendis M, Churchill $\mathrm{S}$, Kohane I. Strategies for maintaining patient privacy in i2b2. J Am Med Inform Assoc 2011 Dec;18 Suppl 1:1103-108.

117. Benton A, Hill S, Ungar L, Chung A, Leonard $\mathrm{C}$, Freeman $\mathrm{C}$, et al. A system for de-identifying medical message board text. BMC Bioinformatics 2011;12 Suppl 3:S2.

118. Meystre SM, Friedlin FJ, South BR, Shen S, Samore MH. Automatic de-identification of textual documents in the electronic health record: a review of recent research. BMC Med Res Methodol 2010;10:70.

119. Tu K, Klein-Geltink J, Mitiku TF, Mihai C, Martin J. De-identification of primary care electronic medical records free-text data in Ontario, Canada. BMC Med Inform Decis Mak 2010;10:35.

120. Dalianis H, Velupillai S. De-identifying Swedish clinical text - refinement of a gold standard and experiments with Conditional random fields. J Biomed Semantics 2010;1(1):6.

121. Aberdeen J, Bayer S, Yeniterzi R, Wellner B, Clark C, Hanauer D, et al. The MITRE Identification Scrubber Toolkit: design, training, and assessment. Int J Med Inform 2010 Dec;79(12):849-59.

122. Gardner J, Xiong L. An integrated framework for de-identifying unstructured medical data. Data Knowl Eng 2009;68(12):1441-51.

123. González DR, Carpenter T, Van Hemert JI, Wardlaw J. An open source toolkit for medical imaging de-identification. Eur Radiol 2010 Aug;20(8):1896-904.

124. El Emam K, Arbuckle L, Koru G, Eze B, Gaudette L, Neri E, et al. De-identification methods for open health data: the case of the Heritage Health Prize claims dataset. J Med Internet Res 2012;14(1):e33.

125. Loukides G, Gkoulalas-Divanis A, Malin B. Anonymization of electronic medical records for validating genome-wide association studies. Proc Natl Acad Sci U S A 2010;107(17):7898-903.

126. O'Keefe CM, Connolly CJ. Privacy and the use of health data for research. Med J Aust $2010 \mathrm{Nov}$ 1;193(9):537-41.

127. Rothstein MA. Is deidentification sufficient to protect health privacy in research? Am J Bioeth 2010 Sep;10(9):3-11.

128. Benitez K, Malin B. Evaluating re-identification risks with respect to the HIPAA privacy rule. J Am Med Inform Assoc 2010 Apr;17(2):169-77.

129. El Emam K, Jonker E, Arbuckle L, Malin B. A systematic review of re-identification attacks on health data. PLoS ONE 2011;6(12):e28071.

130. Brown JS, Holmes JH, Shah K, Hall K, Lazarus R, Platt R. Distributed health data networks: a practical and preferred approach to multi-institutional evaluations of comparative effectiveness, safety, and quality of care. Med Care 2010 Jun;48(6 Suppl):S45-51.

131. Wu Y, Jiang X, Kim J, Ohno-Machado L. Grid Binary LOgistic REgression (GLORE): building shared models without sharing data. J Am Med Inform Assoc 2012 Oct;19(5):758-64.

132. Rogers EM. Diffusion of Innovations, 5th Edition. Simon and Schuster; 2003.

Correspondence to:

Dean F. Sittig, PhD

Center for Healthcare Quality \& Safety

The University of Texas

Health Science Center at Houston (UTHealth)

6410 Fannin St. UTP 1100.43

Houston, TX 77030, USA

E-mail: Dean.F.Sittig@uth.tmc.edu 